Derleme Makale / Review Paper

\title{
Görüntü Analizi Yöntemlerinin Geoteknik Mühendisliğinde Kullanımı
}

\author{
Nihat DiPOVA \\ Akdeniz Üniversitesi, Mühendislik Fakültesi, Antalya \\ Geliş Tarihi (Received): 18.10.2017, Kabul Tarihi (Accepted): 16.01.2018 \\ $\square$ Sorumlu Yazar (Corresponding author*):ndipova@akdeniz.edu.tr \\ (C) +902423106322 且 +902423106306
}

\section{öz}

Görüntü işleme teknolojisi; nesnelerin görüntülerinin bilgisayar ortamına aktarılması ve belirlenen amaç doğrultusunda bilgisayar ile işlenmesini içerir. İnsan gözünün yapabileceği işleri taklit etmeyi amaçlayan görüntü analizi ise günümüz mühendisleri ve bilim insanları için en popüler konuların başında gelir. Son yıllarda artan bir hızla deformasyon ölçümleri, kayma analizleri, boşluk analizleri, dane boyut ve biçim parametrelerinin belirlenmesi, geotekstil özelliklerinin belirlenmesi gibi çözümler için geoteknik mühendisliğinde de kullanılmaktadır. Bu çalışmada; görüntü analiz yöntemlerinin geoteknik mühendisliğinde karşılaşılan problemlerin çözümüne dönük kullanımı araştırılmıştır. Laboratuvarda ve arazide geo-malzemelerin tanımlanmasında ve mekanik davranışın ortaya konması sırasında destekleyici yöntem olarak görüntü analizlerinin kullanımı konularındaki literatür değerlendirilmiş, yöntemin avantaj ve limitleri tartışılmıştır.

Anahtar Kelimeler: Geoteknik mühendisliği, Görüntü analizi, Görüntü işleme, Zemin

\section{Use of Image Analysis Methods in Geotechnical Engineering}

\section{ABSTRACT}

Image processing technology includes transferring of images of objects to a computer and to process by the computer for particular objectives. Image analysis, which aims to mimick tasks that the human eye can do, is one of the most popular subjects for today's scientists and engineers. In recent years, with increasing rate, it is used in geotechnical engineering for solutions such as deformation measurements, shear analysis, porosity analysis, to determine particle size and shape parameters, to determine geotextile characteristics. In this study; possible use of image analysis methods in the solution of the problems encountered geotechnical engineering was investigated. Literature on the use of the image analysis as a complementary method, during identification and reveal of mechanical behavior of rocks and soils in the laboratory and in the field was evaluated, advantages and limitations were discussed.

Keywords: Image analysis, Image processing, Geotechnical engineering, Soil 


\section{GíRiş}

Görüntü işleme teknolojisi; objelerin görüntülerinin bilgisayar ortamına aktarılması ve belirlenen amaç doğrultusunda bilgisayar ile işlenmesini içerir. Ayrıntılı inceleme gerektiren tüm çalışmalarda belirlenen amaca göre görüntü analizleri kullanılabilir. 1960'lı yıllarda uzay araştırmalarında kullanılmak üzere geliştirilen görüntü işleme teknolojileri ve yazılımları, başlıca tıp, genetik, biyoloji, endüstri, tekstil, gıda, jeoloji, madencilik, petrol, bilgisayar, elektronik, inşaat, uzay bilimleri, çevre, fizik ve kimya gibi bilim dallarında uygulama alanı bulmaktadır. Sayısal görüntüleme ve işlemedeki gelişmelere paralel olarak kullanım alanı da genişlemektedir. Amaca yönelik yazılımın seçilmesi görüntü işleme teknolojisinde çok önemli rol oynamaktadır. Ölçüm, sınıflama, renk ve kontras ayarlaması ve filtreleme için uygun yazılımlar kullanılmalıdır. Photoshop vb. programlar kısıtlı da olsa görüntü işleme imkânı sağlar. Seçilen görüntü yakalama aygıtının çözünürlük ve resim özelliklerinin kalitesi yapılacak işlemi doğrudan etkiler. Analizlerin yapılacağı bilgisayar sisteminin performansı da yapılacak işlemleri ve sonuçların niteliğini etkilemektedir.

Görüntü analizi; insan görme sisteminin işleyişini taklit ederek nesnelere ait görüntüler üzerinde hesaplamalar yapılarak anlamlı ve faydalı bilgi üretilmesidir. Farklı uygulamalar için (tıp, malzeme, jeoloji, tekstil vb.) geliştirilmiş görüntü analizi yöntemleri ve özel yazılımlar bulunmaktadır. Son yıllarda artan bir yoğunlukla inşaat mühendisliğinde de; deformasyon ölçümleri, kayma analizleri, boşluk analizleri, dane boyut ve şekil parametrelerinin belirlenmesi, geotekstil özelliklerinin belirlenmesi gibi alanlarda kullanılmaktadır.

Sayısal görüntü elde edildikten sonra, görüntü analizine geçmeden önce, alınan görüntünün hatasız ve kolay işlenebilmesi için daha belirgin ve anlaşılır hale getirilmesi gerekir. Bu işlemler temelde parlaklık, zıtlık, renk gibi görüntüye ait bilgilerin değiştirilmesi; manyetik alan, görüntüleme sırasında hatalı donanım ayarlarının kullanılması gibi nedenlerle oluşan görüntü kirliliklerin (noise) giderilmesi, ayrıntıların daha belirgin hale getirilmesi gibi görüntü kalitesinin iyileştirilmesine yönelik işlemleri içerir ve bu işlemler sonucunda yeni bir görüntü elde edilir.

$\mathrm{Bu}$ çalışmanın amacı, görüntü analiz yöntemlerinin geoteknik mühendisliğinde karşılaşılan problemlerin çözümüne dönük kullanılabilirliğinin araştırımasıdır. Laboratuvarda ve arazide zeminlerin tanımlanmasında ve mekanik davranışın ortaya konmasında destekleyici yöntem olarak görüntü analizlerinin kullanımı irdelenmiş, yöntemin avantaj ve limitasyonları tartışımıştır.

\section{SAYISAL GÖRÜNTÜ}

Sayısal görüntü adından da anlaşılacağı üzere, sayılarla ifade edilen ve bilgisayarın temelini oluşturan ikili sayı sistemi kullanılarak tanımlanan bir veri dosyasıdır. Sayısal görüntüler, ışığı önce elektriksel veriye, daha sonra da sayısallaştırarak sayısal veriye dönüştüren mikroişlemciler aracılığıyla yapılmaktadır (Şekil 1). Günümüzde yaygın olarak $C C D$ (charge-coupled device) ve CMOS (complementary metal-oxide semiconductor) sensörler kullanılmaktadır. CCD sensörlü kameralar kirlilik ve geometrik bozunmanın az olması nedeniyle daha fazla tercih edilmektedir. Kompakt kameralarda mercek (lens), elektronik donanım ile birlikte sabitken, SLR (Single Lens Reflex) kameralarda merceğin değiştirilmesine olanak sağlanmaktadırlar. Bu sayede yapılacak çalışmaya uygun olarak yakın çekim (macro), telefoto veya mikroskop gibi lensler kullanmak mümkün olmaktadır. Görüntü alınırken üç boyutlu cisimler iki boyutlu bir düzleme yansıtıldığından bir miktar perspektif etkisi kaçınılmazdır. Bu etki telefoto lensler kullanılarak ve uzaktan çekim yapılarak inmal edilebilir seviyelere düşürülebilir.

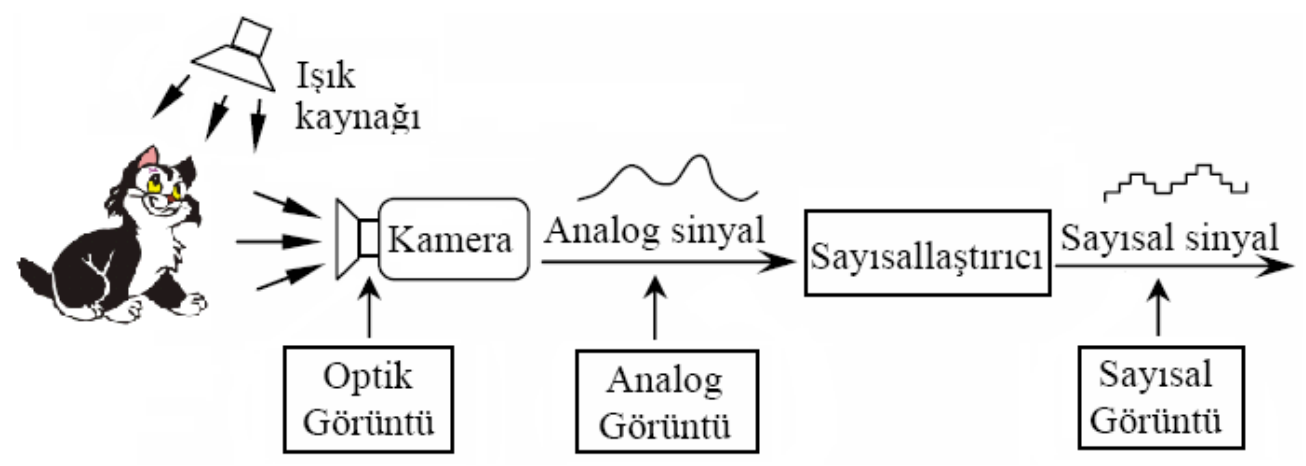

Şekil 1. Sayısal görüntü elde etme 
Nesneden yansıyan ışınlar lens aracılığı ile optik formda kameraya aktarılır. Nesneyi tanımlayan bu ışınlar, kamerada analog elektrik sinyallerine ve bir sayısal dönüştürücüde sayısal sinyallere dönüştürülür. Başka bir deyişle sayısal görüntü, iki boyutlu ışık şiddeti fonksiyonudur. Bu fonksiyon $f(x, y)$ şeklinde gösterilir. Burada $x$ ve y kartezyen koordinatları, $(\mathrm{x}, \mathrm{y})$ noktasındaki f'in sayısal değeri ise parlaklık değeri veya görüntünün ilgili noktadaki gri seviye değeridir (Şekil 2). 256 gri ton seviyesinden oluşan gri seviye ölçekleme birçok çalışmada uygun olmakla birlikte bazı çalışmalarda 24 milyon renkten oluşan renkli ölçek (RGB=kırmızı, yeşil, mavi) de kullanılabilmektedir. Gri ton bir görüntü her pikselde tek bir parlaklık değerine sahipken, RGB bir görüntü de her piksel kırmıZı yeşil ve mavinin bir tonuna sahiptir. Bu üç renk değişkeni farklı yoğunluklarda bir araya gelerek gözün farklı renkler algılamasını sağlarlar. Sayısal görüntünün en basit hali olan ikili (binari) görüntüde ise pikseller 0 veya 1 olmak üzere sadece 2 değer (siyah ve beyaz) alırlar. Çözünürlük, bir görüntüdeki yatay piksel sayısı ve dikey piksel sayısının çarpımı olarak ifade edilir. Alınan görüntünün yüksek çözünürlükte olması analizin başarısını artırmakla birlikte, kullanılan donanımın limitleri açısından önemli sorun oluşturmaktadır.

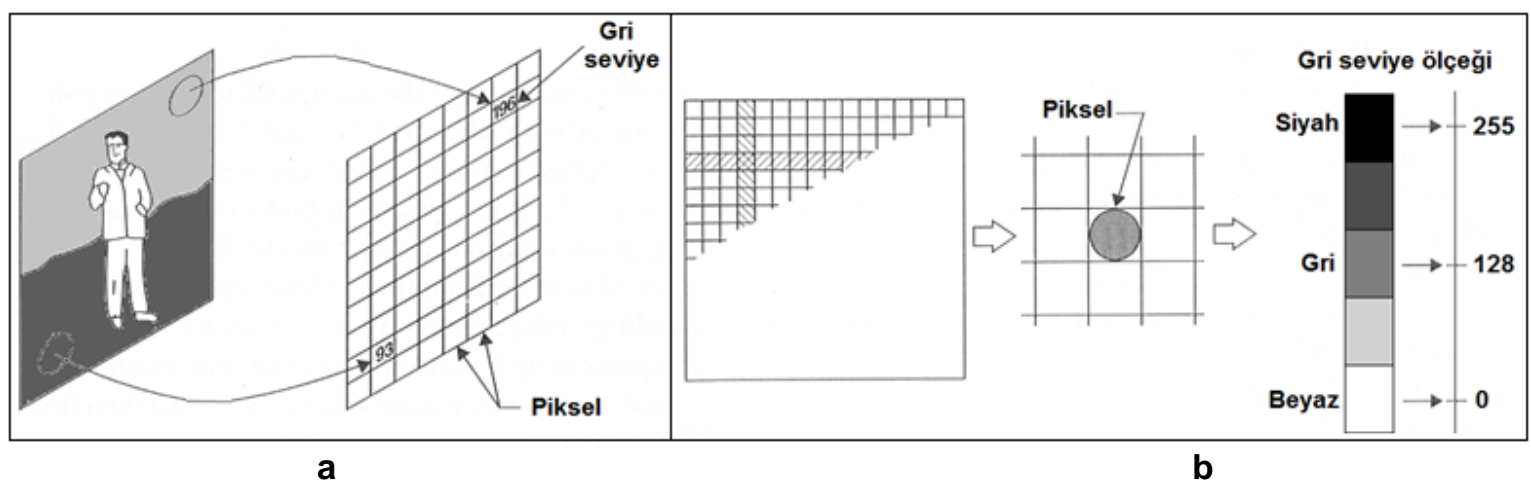

Şekil 2. a) Bir görüntünün gri ton renk ölçeği kullanılarak sayısal forma dönüştürülmesi, b) Bir hücredeki gri tonun 0255 arası dijital veri olarak tanımlanması (Castelman, 1996).

Sayısal görüntü alımında analizin amacına göre, tekli görüntüler, belirli zaman aralıklarında ardışık görüntüler (zaman atlamalı) ve sürekli görüntü (video çekimi) seçeneklerinden biri tercih edilmektedir. Işık kaynağı ve kamera pozisyonlarına bağlı olarak 4 değişik çevre aydınlatma seçeneği vardır; i) Kamera ve ışık kaynağı obje ile aynı tarafta olup, görüntüde görünen, obje tarafından yansıtılan ışık yoğunluğudur, ii) Kamera ve ışık kaynağı objenin ters tarafında olup ekranda açık arka plan üzerindeki objenin koyu biçimi görünür, iii) Olaysal ışık aydınlatması gibi kamera ve ışık kaynağı obje ile aynı tarafta olup, kameraya yansıtılan ışığın bir kısmı görüntü işleme için kullanılır ve açık arkaplan üzerinde koyu renkli objeleri göstermek için kullanılır, iv) Kamera ve ışık kaynağı obje ile aynı tarafta olup sadece saçılan ışık kamera tarafından yakalanır, ve koyu arka plan üzerinde açık renkli objeleri göstermek için kullanıır (Erhardt, 2000) (Şekil 3). Gün ışığı veya noktasal ışık (ampul) kullanıldığında yakındaki objeler ve arka plan üzerine düşen ışık, üniform olmayan bir aydınlatma ve gölgelenme oluşturmaktadır. Bunun sonucunda az ışık alan arka plan objelerle, çok ışık alan objeler farklı ortamlar olarak algılanmakta, veya arka plan ile aynı renk seviyesine sahip olmakta ve bölümleme yapmak oldukça zorlaşmaktadır. Buna çözüm olarak üniform aydınlatma sağlayacak şekilde çok sayıda ışık kaynağı dizi halinde (örneğin LED dizini) kullanılabilir (Dipova, 2017a; Dipova, 2017b). 


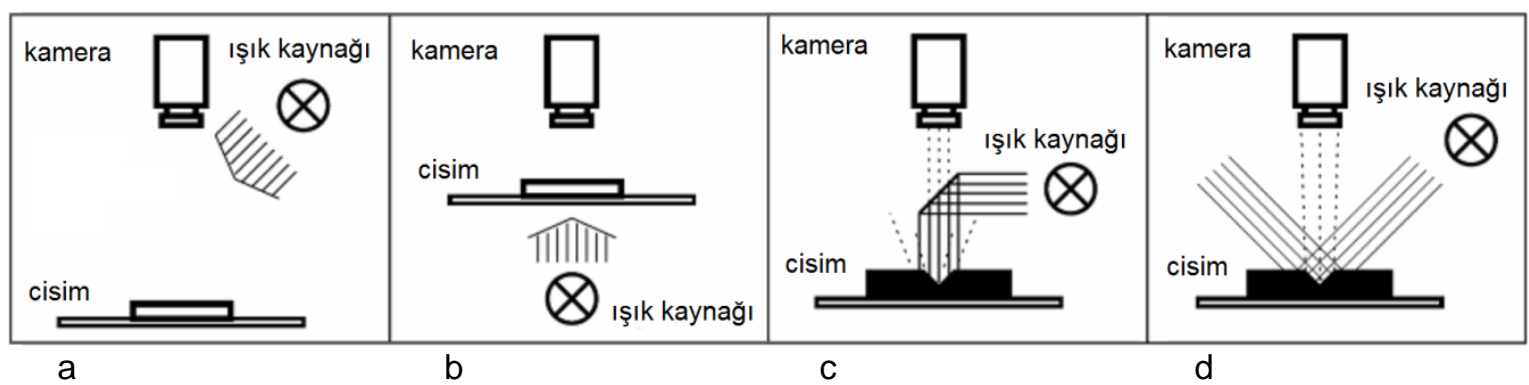

Şekil 3. Çevre aydınlatma seçenekleri; a) Kamera ve ışık kaynağı obje ile aynı tarafta, b) Kamera ve ışık kaynağı objenin ters tarafında, c) Kamera ve ışık kaynağı obje ile aynı tarafta (kameraya yansıtılan ışığın bir kısmı görüntü işleme için kullanılır), d) Kamera ve ışık kaynağı obje ile aynı taraftadır ve sadece saçılan ışık kamera tarafından yakalanır (Erhardt, 2000).

\section{GÖRÜNTÜ IŞLEME YÖNTEMLERI}

Sayısal veri dosyasına dönüştürülen görüntü artık bilgisayar ortamında işlenecek hale gelmiş olur. Görüntü üzerinde yapılacak analiz sürecinde hatasız ve kolay sonuç elde edilebilmesi için daha belirgin ve anlaşılır hale getirilmesi gerekir. Sayısal görüntü işleme temelde parlaklık, kontrast, renk vb. görüntüye ait bilgilerin değiştirilmesi; manyetik alan, görüntüleme sırasında hatalı donanım ayarlarının kullanılması vb. nedenlerle oluşan görüntü kirliliklerin (noise) giderilmesi, detayların daha belirgin hale getirilmesi (sharpening) gibi görüntü kalitesinin iyileştirilmesine (image enhancement) yönelik işlemleri ifade eder (Baxes, 1994; Gonzalez ve Woods, 2001; Young ve ark., 1998). Aşağıda bazı temel görüntü işleme yöntemleri kısaca tanıtılacaktır.

Kontrast geliştirme: Kontrast (veya karşıtlık), görüntünün ayırt edilebilirliğini ifade eder. Gözün gri değerleri ayırt etme kapasitesi ortalama olarak otuz gri değerle sınırlıdır. Bir görüntüdeki en düşük ve en yüksek gri değerleri arasındaki farkın bu sınırdan düşük olması durumunda, detaylar yeterince algılanamaz. Bu görüntülerde, gri düzeyli bir görüntünün dar bir aralığında çok sayıda piksel yoğunlaştığından, çeşitli dönüşüm fonksiyonları yoluyla karşıtlığın ayarlanması gerekir.

Gölge Düzeltme: Nesnelerin sayısal görüntüleri elde edilirken, ışık, kamera veya diğer nesneden kaynaklanan görüntü üzerinde belirgin gölgeler oluşabilir. Görüntü merkezde parlak kenarlara yaklaştıkça koyulaşan veya bu durumun tam tersi şekilde merkezde koyu kenarlara doğru parlaklaşan bir yapı içinde olabilir. Görüntünün sağından soluna giderken parlaklık azalabilir yada artabilir. Gölgelenme, uniform olmayan aydınlatma veya lensin lekeli, çizik veya kirli olmasından da kaynaklanabilir. İmaj analizi aşamasından önce görüntünün bu durumdan kurtarılması zorunlu hale gelmektedir.

Keskinleştirme: Genel fotoğrafçılıkta da iyi bilinen bir görüntü iyileştirme yöntemi olan keskinleştirme (sharpen) görüntüdeki kenarların belirginleştirilmesidir. Keskinlik maskesiyle bir görüntüdeki sınır bölgelerinin (kenarlar) iyileştirilmesi demek ilk önce bu kenarların resimden ayrılması, sonra güçlendirilmesi ve tekrar görüntüye eklenmesi olarak tanımlanabilir.

Kirlilik Giderme: Kirlilik giderme işlemi için kullanılan lineer filtreler içerisinde optimal filtreleme işlemini Wiener Filtresi vermektedir.

Bozunma (Distorsiyon) Giderme: Gerçek bir dijital görüntü sadece kirlilik değil bunun yanında, lens, kamera veya objenin hareketi gibi değişik etkenler sebebiyle de görüntü kayıpları yaşar. Wiener filtresi, medyan filtreleri kullanımı sonrasında imajın görsel kalitesi artmaktadır.

\section{GÖRÜNTÜ ANALIZIi YÖNTEMLERI}

Görüntü analizi; insan görme sisteminin işleyişini taklit ederek nesnelere ait görüntüler üzerinde hesaplamalar yaparak; ölçme, değerlendirme ve karar verme süreçlerini içerir. Sayısal görüntü analizinde genellikle yapılan işlemler sonucunda yeni bir görüntü elde edilmez, ancak görüntüye ait değerlendirmeler yapılabilir, görüntüyle ilgili istatistikler üretilir. Sayısal görüntü analizinde nesnelere ait parametrelerin (şekil, uzunluk, alan, açı, göreli konum, dokusal yapı, gri-ton değeri, RGB renk değerleri vb.) ölçülmesi söz konusudur. Aşağıda bazı temel görüntü analizi yöntemleri kısaca tanıtılacaktır.

Eşikleme: Görüntü işlemede en çok kullanılacak tekniklerden biri eşiklemedir (treshold). Gri ton eşiklemesinde bir eşik değer seçilerek, açık ton üzerinde koyu kısımların yada tersi olarak koyu zemin 
üstünde parlak kısımların aranması hedeflenir. Bunun sonucunda "obje" ve "arka plan" olarak iki kısım belirlenir. Eşik değerin belirlenmesi için görüntünün parlaklık histogramı çıkartılır. Yüksek değere sahip olan kısımlar daha açık renkteki kısımları, yani bu görüntü için arkaplanı göstermekte, daha düşük değerde olan kısımlar ise objeleri göstermektedir. Renkli görüntülerde ise bir piksel temelde üç renk bileşeni içerir (RGB: kırmızı,yeşil, mavi). Bu bileşenlerin her biri bir byte ile anlatıldığında her bir piksel $255^{\star} 255^{\star} 255$ farklı renk değeri alabilir. Bir pikselin ikili uzaya aktarılması onun renk bileşenlerinin tümünün 255 ya da tümünün 0 olması anlamına gelir. Bunun için de piksel renk bileşeni bir sınırdan büyükse 255 küçükse 0 yapılır. RGB renk uzayı ışığı temel alarak, doğadaki tüm renklerin kodları bu üç temel renge referansla belirtilir. HSV (Hue, Saturation, Value) veya HSB (Hue, Saturation, Brightness) renk uzayında ise renkleri sırasıyla renk özü, doygunluk ve parlaklık olarak tanımlar. Renk özü, rengin baskın dalga uzunluğunu belirler, örneğin sarı, mavi, yeşil, vb. Açısal bir değerdir $\left(0^{\circ}-360^{\circ}\right)$. Doygunluk ise rengin canlılığını belirler. Yüksek doygunluk canlı renklere neden olurken, düşük olasılık rengin gri tonlarına yaklaşmasına neden olur ve 0-100 arasında değişir. Parlaklık ise rengin aydınlığını yani içindeki beyaz oranını belirler. 0-100 arasında değişir. RGB ve HSV nin bileşenlerinin histogramları üzerinde seçim yapılarak eşikleme gerçekleştirilir (Şekil $4 b-c)$.
Bölümleme: Nesnelerin görüntülerinin analiz edilmelerinde öncelikli olan konu görüntü üzerinde "ilgilenilen kısım" ve "geri kalanı" arasındaki farkı ayırt etmektir. Görüntü içerisinde ilgilenilen kısmı bulmaya yarayan tekniklere bölümleme (segmentation) teknikleri denmektedir. Bununla ilgili olarak, her pikselin objeye ait olup olmadığının kontrolü gerekmektedir. Bu yolla ikili (binary) görüntü üretilir. Eğer piksel objeye aitse "1" değerini, değilse "0" değerini alır. Bölümleme, düşük seviye görüntü işleme ile görüntü analizi arasındaki eşik işlemidir. Bölümleme sonunda hangi pikselin hangi objeye ait olduğu anlaşılır. Görüntü alanlara ayrılır ve süreksizlikler alanlar arasındaki sınırları oluşturur. Ayrıca bölümleme sonucunda objelerin şekilleri de analiz edilebilir (Şekil 4d).

Kenar Bulma: Eşikleme tekniğine alternatif bir bölümleme işlemi de objelerin sınırlarını belirleyen piksellerin bulunmasını sağlayan bir bölümleme tekniği olan kenar bulma tekniğidir (Şekil 4e). Eşik değer filtresi ayrım yapmak için objeye ait olan tüm pikselleri hesaba katar. Bu yönteme alternatif olarak objenin sınırlarına ait olan pikselleri bulmak için teknikler geliştirilmiştir. En yaygın yöntemlerden biri olan zincir kodu yönteminde sınır piksellerinin tamamının yerlerinin kaydedilmesi yerine başlangıç pikselinin seçilip, koordinatının tanımlanması yeterlidir. Uygulanacak bir algoritma sayesinde objenin sınırları belirlenebilir.

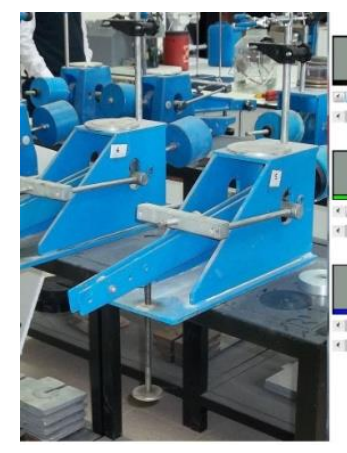

a

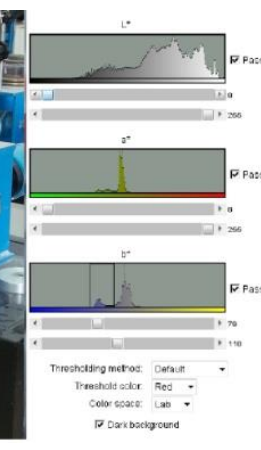

b

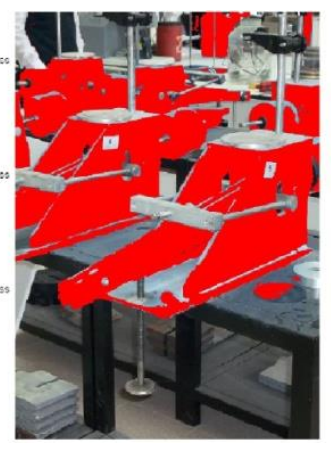

C
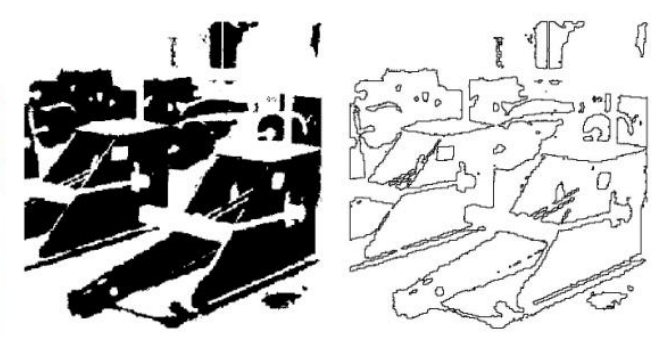

d

Şekil 4. a) RGB görüntüsü, b) Açık mavi renkli bölgelerin renk eşiklemesi, c) Eşiklenmiş bölgeler (kırmızı boyanmış), d) Bölümlenme sonrası binary görüntü, e) Binary görüntü üzerinde kenar bulma.

Havza (watershed) Ayırma: Nesnelerin teması ve örtüşmesi sayısal görüntülerin analizinde önemli bir sorun olmaktadır. Bu sorunun otomatik olarak çözümü için Beucher ve Lantuejoul (1979) havza sınırı ayırma algoritması geliştirmiştir. Bu algoritma daha sonra Vincent ve Soille (1991) tarafından modifiye edilmiştir. Bu yöntem ikili (binary) görüntüdeki cisim üzerinde uzaklık dönüşüm algoritması uygulanması ve topoğrafyadaki havza sınırı mantığıyla, birbiri üstüne bindirme durumundaki nesneler arasına yapay bir sınır oluşturmaktadır (Şekil 5). 

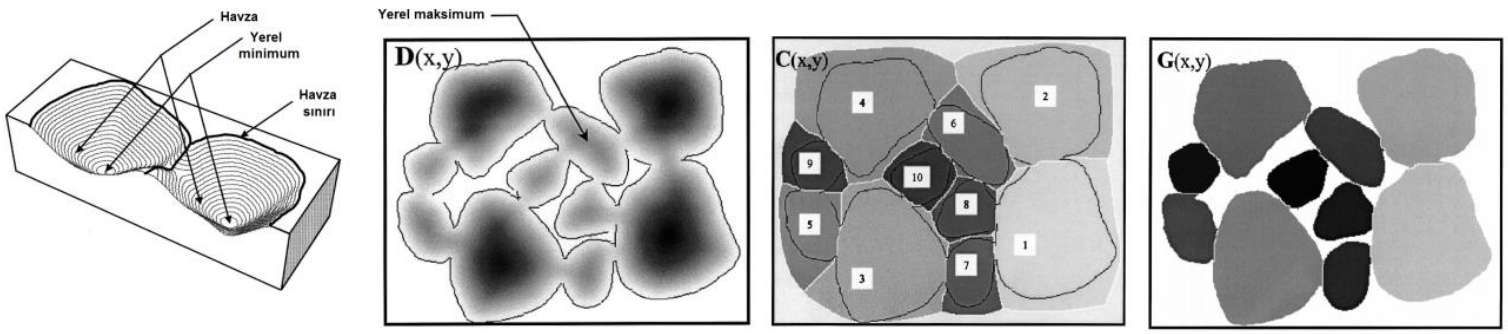

Şekil 5. Havza (watershed) ayırma (Raschke ve Hryciw, 1997)

\section{GEOTEKNIKTE GÖRÜNTÜ ANALIZI UYGULAMA- LARI}

$\mathrm{Bu}$ bölümde, geoteknik mühendisliği çalışmalarında geleneksel yöntemlerle ölçüm yapıldığında sınırlamalarla karşılaşılan; dane boyu dağılımı, dane şekil analizi, porozite tayini, blok/matris oranı, büzülme, hacim değişimi ve bazı deformasyon analizleri için literatürde uygulanmış olan görüntü analiz yöntemleri tanıtılacaktır.

Dane boyu ve dane şekli: Görüntü analizinin geoteknikte ilk kullanım alanı bulduğu konulardan biri dane boyu dağılımıdır. Zemin mekaniğinde elek analizi yöntemiyle tane boyu dağılımı belirlenmesinin uzun ve zahmetli olması ve özellikle uzun danelerde hatalı sonuçlar ortaya çıkmasından ötürü dane boyu dağılımının görüntü analiz teknikleri kullanılarak belirlenmesi bazı araştırmacılar tarafından araştırılmıştır (King, 1984; Hyoungkwan ve ark., 2003; Mora ve ark., 1998; Ghalib ve Hryciw, 1999; Mora ve Kwan, 2000; Mertens ve Elsen, 2006; Dipova, 2017a). Dipova (2017a) tarafından kurulan görüntü alma düzeneği ve deney sonuçları şekil 6'da gösterilmektedir. Kullanılan ekipmanın kum boyutundan küçük danelerin görüntülenmesinde yetersiz kalması nedeniyle bu çalışmalar iri taneler üzerinde yoğunlaşmıştır. Bilgisayarlı tomografi (CT) ve SEM sistemleri kullanılarak küçük boyutlardaki danelerin görüntülenmesi ve analizi denenmiş olsa da ekonomik ve pratik olmadığı anlaşılmıştır (Nielsen, 2004). Hryciw ve Raschke (1996), CPT (koni penetrasyon deneyi) sondasının yan yüzeyine yerleştirilen kamera ile alınan görüntüleri analiz ederek, numune alımının mümkün olmadığı CPT deneyi yapılırken dane boyu dağııım analizini de gerçekleştirmişlerdir.
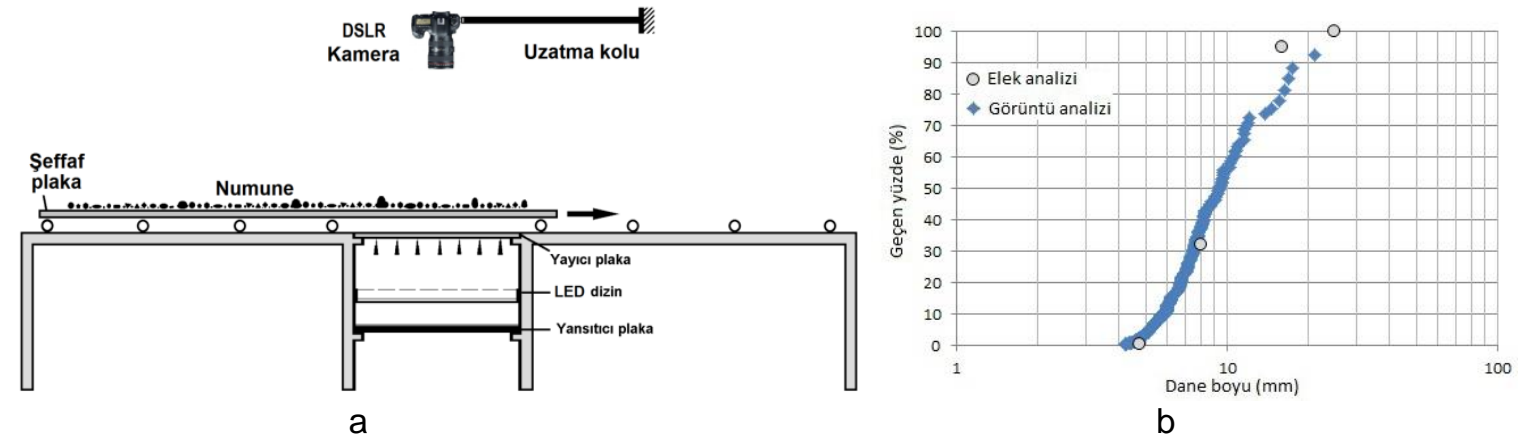

Şekil 6. a) Alttan aydınlatmalı kayar tabla, b) Elek analizi ile karşılaştırma (Dipova, 2017a).

Daneler sayısal ortama taşındıktan sonra biçimlerinin analiz edilmesi de söz konusu olabilmektedir (Kwan ve ark., 1999; Brzezicki ve Kasperkiewicz, 1999; Mora ve Kwan, 2000; Al-Rousan, 2004; Alshibli ve Alsaleh, 2004). Görüntü alınan düzenekte danelerin birbirine dokunması durumunda, dokunan daneler tek bir dane olarak algılanacağından, hem boyut hem de şekil ölçümü hatalı olacaktır. Dane sayısının fazla olduğu ve ard arda çok sayıda deney yapılacağı durumlarda danelerin el ile ayrıştırılması pratik olmayacağından, Dipova (2017a) zeminin yerleştirildiği tablaya vibratör dokundurarak bir çözüm üretmiştir. Bu sorunun görüntü üzerinde çözümü için, dokunan danelerin sayısal olarak ayrıstırılmasını sağlayan havza sınırı algoritması uygulamıştır (Ghalib ve Hryciw, 1999; Raschke ve Hryciw, 1997).

Porozite: Literatürde porozite belirlenmesinde görüntü işleme tekniklerinin kullanımı ile ilgili bazı çalışmalar bulunmaktadır. Crabtree ve ark. (1984), epoksi emdirilmiş kaya malzemesindeki boşlukları, renk bölümleme analiz tekniğini kullanarak karakterize etmiştir. Ruzyla (1984) boşluk yapısını karakterize etmek için bir nicel görüntü analiz sistemi tasarlamış ve geleneksel ince kesit teknikleri kullanılarak mümkün olmayacak boşluk parametrelerini elde etmiştir. Muhunthan ve ark.. 
(2000), kum numunelere reçine emdirip, kesitler hazırlayıp bu kesitler üzerinde görüntü analizi yaparak üniformluk, anizotropi, porozite, dane çapı, efektif boşluk çapı ve özgül yüzey ölçümlerini yapmışlardır. Frost ve Jang (2000) kum numuneler düşük basınçta epoksi emdirerek katılaştırıp, kesitler alarak yerel boşluk oranı dağılımını incelemiştir. Bhatia ve Soliman (1990) içine epoksi enjekte edilen kum numunelerin boşluk oranı dağılımını belirlemişlerdir. Kuo ve Frost (1996), reçine emdirilen kum numunelerden kesitler alıp görüntü analizi yaparak zeminin porozitesini belirlemişlerdir. Hu ve ark. (2005) sıkıştırıımış kil dolguların iç yapısındaki değişimi görüntü analizi ile incelemişlerdir. Elektron mikroskobu görüntüleri üzerinde boşluk dağılımı ve dane boyutları analiz edilmiştir.

Çatlaklı kayalar, birincil boşluk içeren kayalar, erime boşlukları içeren kayalar ve ayrışmış kayalarda boşluk hacmi ölçümleri ve buna bağlı porozite belirlenmesi önemli yer tutar. Porozitenin belirlenmesi ile ilgili uygulanan deney yöntemleri (ASTM C97, TS 699) boşluk hacmi ve su yer değiştirmesi prensibine dayanır. Bu amaçla numuneler suya doyurularak boşluk hacmine denk su hacmi belirlenir. Bu işlem zaman alıcı ve zah- metli olmakla birlikte suya karşı direnci zayıf ve boşlukları bir biri ile bağlantılı olmayan örneklerde yanıltıcı sonuçlar verir. Boşlukları bir birleriyle bağlantılı olmayan ve kısmen dolgulu halde bulunan vesiküler bazalt kayasında klasik yöntemlerle porozite belirlenemediğinden Al-Harthi ve ark., (1999) kayaç üzerinden ince kesitler alıp fotoğraflayarak görüntü analizi teknikleri yardımıyla poroziteyi belirlemişlerdir. Dipova (2014) makro boşluklu tufada karot yüzeylerinin taranması sonrasında elde edilen yan yüzey görüntüleri üzerinde görüntü analizi yaparak poroziteyi belirlemiştir (Şekil 7).

Aydilek ve Edil (2004), çeşitli matematiksel morfoloji algoritmaları izleyerek, görüntü analizi yöntemi ile geotekstillerde gözenek açıklıklığı boyutlarının ölçümünü yapmış ve açık alan yüzdesi değerlerini belirlemiştir. Örgüsüz geotekstillerde lif ve boşluk boyutlarını içeren mikro yapı karakterizasyonu Aydilek ve ark. (2005) tarafından yapılmıştır. Taramalı elektron mikroskobu (SEM) görüntüleri üzerinde görüntü analizi yapılarak geotekstillerin tıkanma ve bloke olma durumları karakterize edilmiştir (Aydilek, 2006).

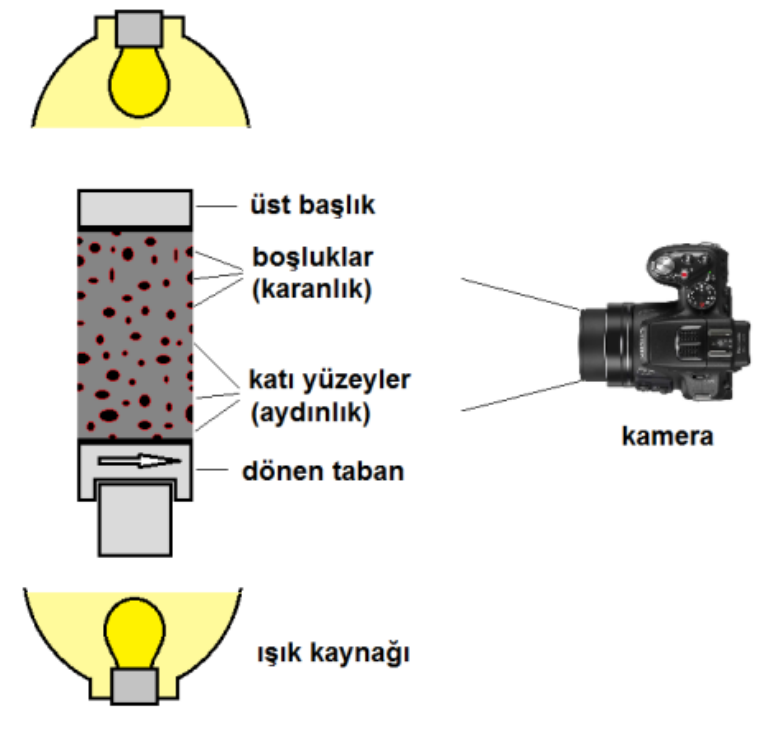

a

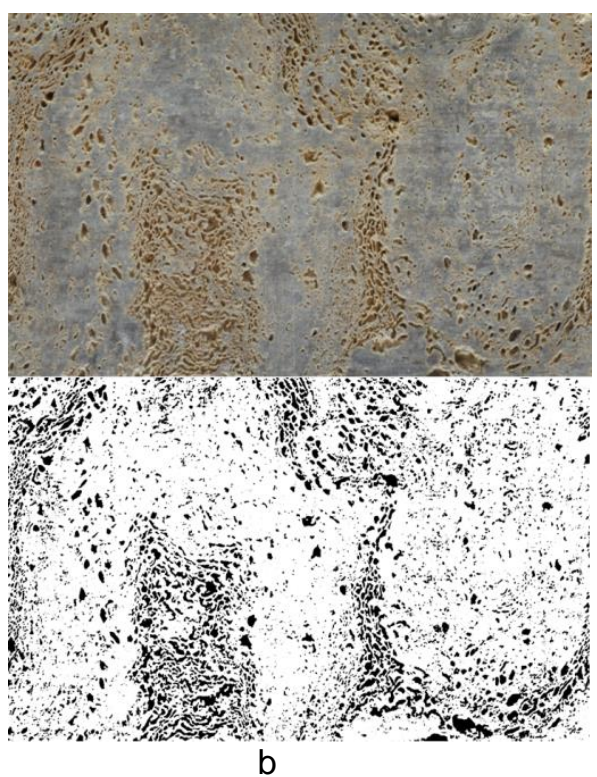

$\mathrm{b}$

Şekil 7. a) Karot yan yüzey tarama düzeneğinin şematik gösterimi, b) Yanal yüzey doğal görüntüsü (üstteki görüntü), işlenmiş ve sınıflanmış ikili (binary) görüntü (alttaki görüntü) (Dipova, 2014)

Blok/matris oranı: Matris içinde blok içeren zeminlerin mekanik davranışı blok/matris oranı ile ilişki içindedir. $\mathrm{Bu}$ tür malzemeler gerilme altında kompozit olarak davranmakta ve toplam gerilme ve deformasyon bileşenler arasında pay edilmektedir. Bu nedenle blok ve matrisin kapladığı hacim ve bunlar arasındaki oranın belirlenmesi gerekmektedir. Tanımlama parametrelerinden biri olan hacimsel blok oranı, blok hacminin top- lam hacme oranı ile elde edilir. Bazı araştırmacılar (Goodman ve Ahlgren, 2000; Haneberg, 2004; Medley, 2002; Kahraman ve ark., 2010) hacimsel blok oranının belirlenmesi ile ilgili çalışmalar gerçekleştirmişlerdir. Bazı bloklu ortamlarda belirgin olarak iki bileşen bulunur ve gri ton eşiklemesi yapılarak blok/matris oranı kolaylıkla bulunabilir. Birden fazla bileşen olduğunda, birden fazla renk söz konusu olacağından gri ton eşik- 
lemesi yeterli olmayacağından RGB veya HSV uzayı histogramlarında renk eşiklemesi gerçekleştirilir. Şekil 8'de renk eşiklemesi yardımı ile bir RGB görüntüden blok ve matris bölümlemesi yapılması gösterilmektedir (Dipova, 2014). Ayırt edilmesi istenen blok veya matrise ait bölüm, renk, doygunluk ve parlaklık görüntü his- togramından seçilmekte ve bunun dışındaki kısımlar farklı bir renkle kodlanmaktadır. Böylece blok veya matristen birisi bir renk değeri ile ifade edilmekte, geri kalanı ise ikinci renkle kodlanarak ikili (binary) kod elde edilmektedir.

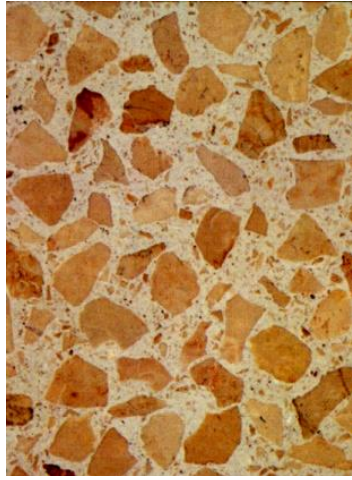

a

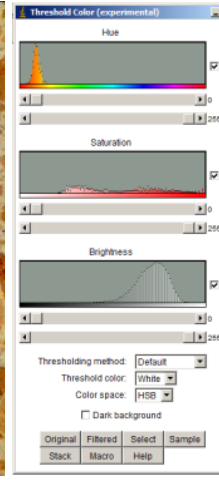

b

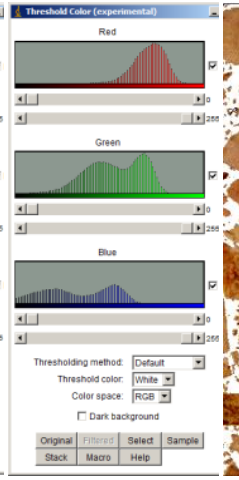

C

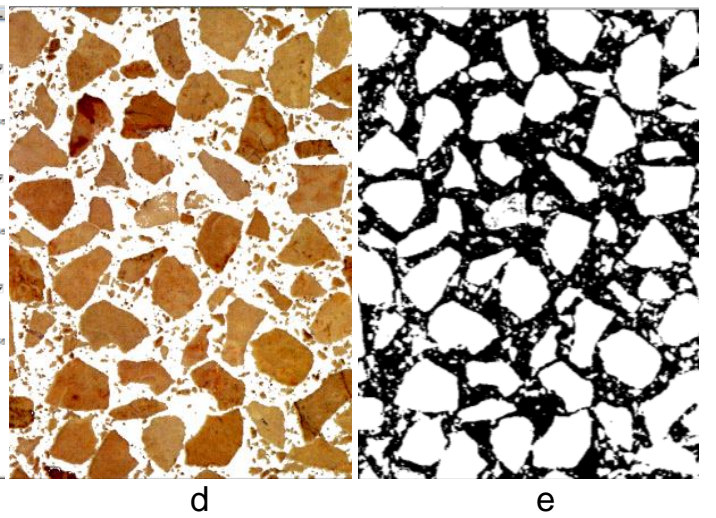

Şekil 8. RGB ve HSB histogramları kullanılarak renk eşiklemesi yapılması, a) RGB görüntü, b) HSB Histogramı c) RGB Histogramı, d) Sadece matris üzerinde renk eşiklemesi yapılarak blok haricindeki kısımların eşiklenmesi, e) Matris haricindeki kısımların da bölümlenmesi İle blok ve matrisin ikili (binary) olarak kodlanması (Dipova, 2014)

Deformasyon ölçümü: Görüntü analizi yöntemlerinin geoteknikte bir baska kullanım alanı bulduğu konu laboratuvar deneylerinde deformasyon ölçümüdür. Zemin mekaniğinde gerilme-deformasyon ilişkilerinin çıkarılmasında doğrudan deformasyon ölçümleri tercih edilmektedir. Bu amaçla analog veya dijital komparatörler, elektronik sensörler (potensiyometrik cetvel) veya lazer ölçüm cihazları kullanılabilmektedir. Ancak deformasyonun üniform olmadığı durumlarda sınırlı sayıda bölgeden alınan ölçümlerle yetinilmekte ve bazı varsayımlarla ölçümler desteklenmektedir. Bu nedenlerle doğrudan ölçülüyor olsa da ölçüm mekanik davranışı temsil edememektedir. Örneğin lastik balya kayma testinde gerek numune boyutu gerekse deformasyonun üniform olmayışı nedenleriyle mekanik ölçüm yöntemleri yetersiz kaldığından, Freilich ve Zornberg (2010) test sırasında video kayıt yaparak yüke karşılık gelen deformasyonu görüntü analizi ile belirlemişlerdir (Şekil 9). Zemin mekaniğinde deformasyon ölçümlerinde önemli bir sorun da tek eksenli ve üç eksenli basınç deneylerinde yaşanmaktadır. Silindirik zemin numunesinde deney boyunca sadece boy değişimi ölçülmekte, kesit alanındaki genişleme üniform kabul edilerek hesaplama yoluyla bulunmaktadır. Oysa gerçekte deney boyunca numune silindir geometrisini kaybedip fıçı şekline ben- zer halde deforme olmaktadır. Yükün alana bölünmesi biçiminde hesaplanan gerilme değeri ise yaklaşık bir değer olarak kalmaktadır. Güler ve ark. (1999), doğrudan kesme deneyinde kum danelerinin göçme öncesi yaptıkları yerdeğiştirmeleri hücreye yerleştirilen kamera yardımıyla incelemişlerdir. Cheng ve ark. (2001) ödometre hücresine yerleştirilen kamera ile, granüler zeminlerde yükleme sonrası dane boyutu ve şeklinde gerçekleşen değişimleri incelemişlerdir. Dipova (2017b), serbest basınç deneyinde numunedeki değişimi zaman atlamalı görüntüler üzerinden görüntü analizi ile gerçekleştirmiştir (Şekil 10). Görüntü analizi yardımı ile kum zeminlerde, Alshibli ve Sture (2000) düzlem birim deformasyon deneylerde, Alshibli ve ark. 2003 ise üç eksenli basınç deneylerinde deformasyon ölçümleri gerçekleştirmiştir. Üç eksenli basınç deneylerinde zemin örneklerinin hacim değişimlerinin hesaplanmasında da sayısal görüntü analizi yöntemleri başarı ile uygulanmıstır (Macari ve ark., 1997; Alshibli ve AlHamdan, 2001). Aydilek ve ark. (2007) görüntü analizlerini geosentetik çekme deneylerinde deformasyonların izlenmesi için kullanmışlar, ve endüstride kalite kontrol amaçı olarak da faydalı bir yöntem olacağı sonucuna varmışlardır. 


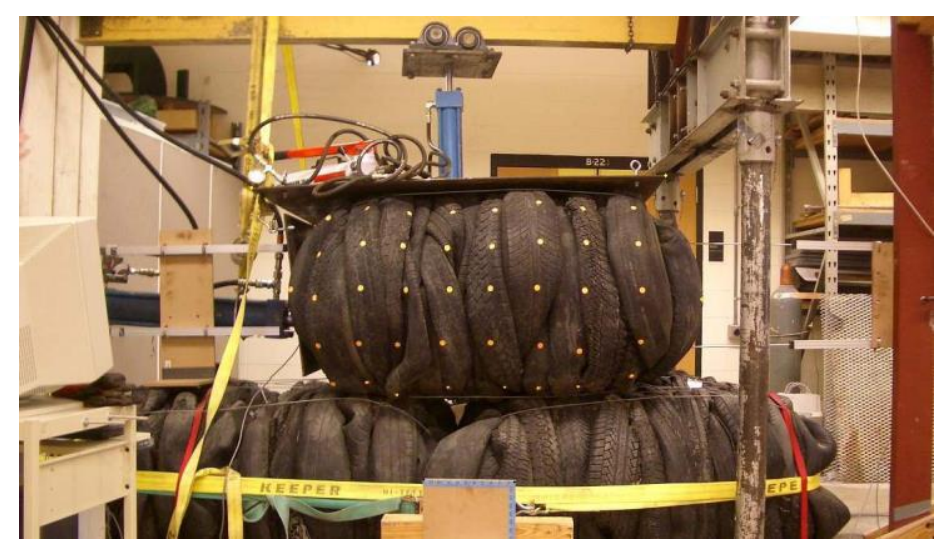

Şekil 9. Lastik balya için büyük ölçekli doğrudan kesme deneyi düzeneğinde deformasyon ölçümü, sarı noktaların yer değiştirmelerinin görüntü analizi ile belirlenmesi yoluyla gerçekleştirilmiştir (Freilich ve Zornberg, 2010)

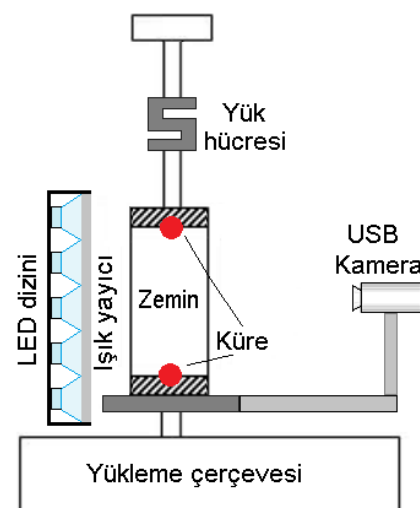

a

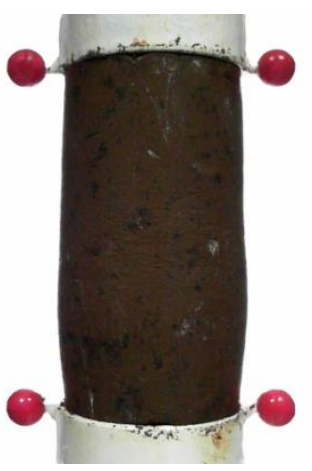

b

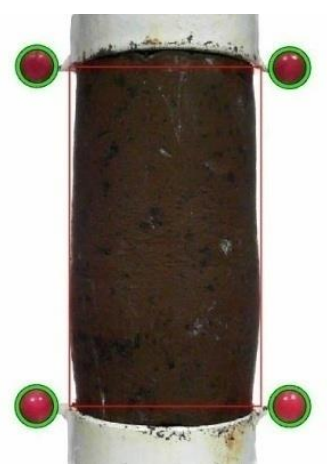

C

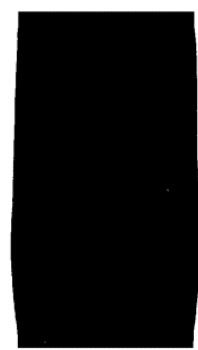

d

Şekil 10. a) Deney düzeneği, b) Özgün görüntü, c) Analiz edilmiş görüntü, d) Bölümleme sonrası binary görüntü (Dipova, 2017b)

Büzülme: Killi zeminler kuruduklarında hacim kaybına uğrarlar ve yüzeyde çatlaklar oluşur. Bu sürece büzülme denir ve mühendislik açısından dayanımda azalma ve sıkışabilirlikte artış anlamı taşır. Killerde büzülme, şişme ve erozyon davranışı ile de ilişki içindedir. Zeminlerin büzülme davranışı; büzülme limiti, lineer büzülme ve hacimsel büzülme olmak üzere üç indis ile tanımlanmaktadır. Amerikan Deney ve Malzeme Derneği (ASTM) büzülmenin ölçülebilmesi için bir standard yöntem tanımlamıştır (ASTM D427-83). Bu yöntemde büzülme hacmi civa $(\mathrm{Hg})$ yer değiştirmesi ile belirlenmekte ve civanın toksik bir malzeme olmasından ötürü alternatif yöntem olarak parafin kaplama yöntemi önerilmiştir (ASTM D4943). Birinci yöntemde olduğu gibi toksik tehlike olmasa da, bu yöntemde de sıcak parafinin cilde zarar vermesi tehlikesi vardır. Ayrıca her iki yöntem de zahmetli ve zaman alıcı yöntemlerdir. Killi zeminlerde oluşan büzülmenin görüntü analizi yoluyla tespit edilmesi üzerine literatürde çalışmalar bulunmaktadır. Peng ve ark. (2006) zeminlerin kuruma sırasında gösterdikleri hacim değişimini, çatlak gelişimini ve çatlakların geometrik analizlerini görüntü analizi ile gerçekleştirmiştir. Tang ve ark. (2008) görüntü analizi ile, kil zeminin büzülme davranışına sıcaklık, katman kalınlığı, ıslanma-kuruma döngü sayılarının etkilerini araştırmıştır. Ören ve ark. (2006) sıkıştırılmış kil zeminlerde küçük birim deformasyon seviyelerinde hacimsel büzülmenin nicel olarak belirlenmesi amacıyla görüntü analizi yönteminden yararlanmışlardır. Dipova (2014) üniform yüzey aydınlatması sağlamak amacıyla numune kenarından LED şerit ışık ile yatay aydınlatma uygulamış, görüntü işleme ile zenginleştirildikten sonra, görüntü ikili olarak kodlanmış ve alan oranları belirlenmiştir (Şekil 11). 


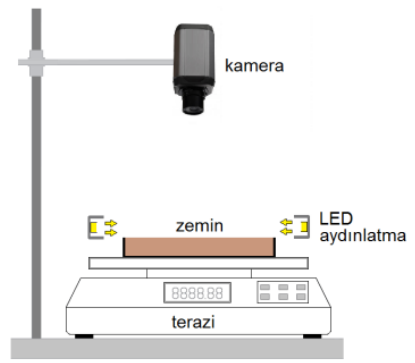

a

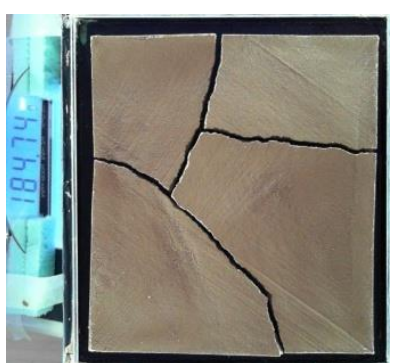

b

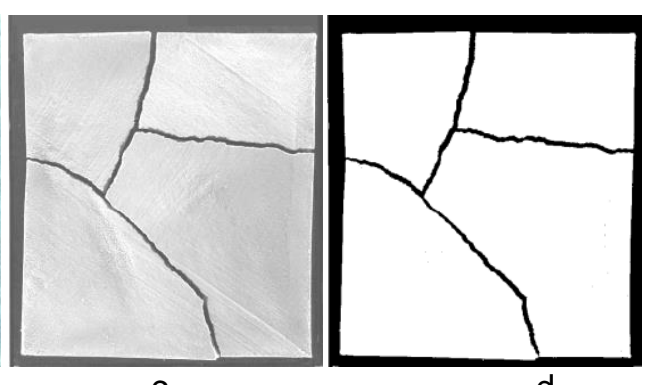

C

d

Şekil 11. a) Büzülme görüntü analizlerinde kullanılan düzenek, b) Numunenin büzülme ve çatlama sonrasında kalıp içinde görünümü ve anlık ağırlığı, c) Bölümleme öncesi parlaklık ve zıtlık ayarı yapılması, d) Bölümleme sonrası ikili kodlu (binary) görüntü (Dipova, 2014)

\section{SONUÇLAR}

$\mathrm{Bu}$ çalışmada, laboratuvarda ve arazide geomalzemelerin tanımlanmasında ve mekanik davranışın ortaya konması sırasında destekleyici yöntem olarak görüntü analizlerinin kullanılabilirliği değerlendirilmiştir. Değerlendirmeler sonucunda aşağıdaki sonuçlar elde edilmiştir.

i) Görüntü analizleri dane boyu dağılımı çalışmalarında kullanıldığında, geleneksel elek analizlerine göre avantajlar içermektedir. Elek analizinde sadece belirli aralıktaki dane boyu için yüzdeler belirlenirken görüntü analizi yönteminde analize giren her bir danenin kayda alınması ve tüm geometrik özelliklerinin ölçülmesi mümkün olabilmektedir. Elek analizindeki eşdeğer boyut kavramı danenin ortanca boyutunun elek gözü köşegenine eşit olması varsayımı ile bir sınırlama söz konusu iken görüntü analizinde dane boyu dağılımı istenilen dane boyutlarından biri için yapılabilir. Bu avantajlara karşın görüntü analizlerinin en büyük dezavantajı deneyde az miktarda numune kullanılmasından ötürü zemin kütlesini temsil etme yetersizliğidir. Bu husus çok sayıda deney yaparak aşılabilir ancak bu durumda da çok zaman ve emek harcamak gerekir. Bu dezavantaj da sadece dane boyu analizi yapmaya yönelik gelişmiş düzenekler tasarlanarak çözülebilir.

ii) Görüntü analizleri ile makro boşluklu geomalzemelerde boşluk hacmi ölçümleri ve buna bağlı porozite belirlenmesi pratik bir şekilde yapılabilmektedir. Geleneksel yöntemler zaman alıcı ve zahmetli olmakla birlikte suya karşı direnci zayıf ve boşlukları bir biri ile bağlantılı olmayan örneklerde yanıltıcı sonuçlar vermektedir. Bu bağlamda, görüntü analizleri önemli bir intiyaca cevap verebilir.

iii) Matris içinde blok içeren malzemelerin blok ve matrisin kapladığı hacim ve bunlar arasındaki oranın belirlenmesi temel görüntü analizi yöntemleri ile mümkün olabilmektedir. Blok ve matris arasında belirgin renk, kontrast, parlaklık ve doygunluk farkı oluştuğundan, renk eşiklemesi uygulaması ile görüntünün ikili (binary) görüntüye dönüştürülmesi mümkün olmaktadır. İkili görüntü elde edildikten sonra da blok/matris oranı otomatik olarak belirlenebilmektedir.

iv) Deformasyon ölçümlerinde geleneksel yöntemler kullanıldığında deformasyonun üniform olmadığı durumlarda sınırlı sayıda bölgeden alınan ölçümlerle yetinilmekte ve bazı varsayımlarla ölçümler desteklenmektedir. Bu nedenlerle doğrudan ölçülüyor olsa da ölçüm mekanik davranışı temsil edememektedir. Zemin mekaniği basınç deneylerinde görüntü analizi ile deformasyon ölçümü yapıldığında, üniform deformasyon kabul edilerek bulunan kesit alanındaki değişime nazaran daha gerçekçi olarak kesit alanının belirlenebildiği anlaşılmıştır. Bu fark yükün alana bölünmesi biçiminde hesaplanan gerilme değerine de yansımaktadır.

v) Killerde büzülme davranışı görüntü analizleri ile incelenebilmektedir. Geleneksel yöntemler olan civa ve parafin yöntemlerinde, civanın toksik bir malzeme oluşu, sıcak parafinin ise cilde zarar vermesi tehlikesi olduğundan görüntü analizi yönteminin uygulamada yer bulacağı düşünülmektedir. Hacim değişiminin durması (büzülme limiti) ortalama 3 gün sürmektedir. Ancak görüntü analizinde işlemler tümüyle otomatik olarak sürdürüldüğünden bu süre içinde insan emeği ve zamanı söz konusu değildir.

vi) Sınırlı sayıda deney söz konusu olduğunda hazır yazılımlar kullanılabilir. Numune sayısı arttığında ve otomatik işlemler gerektiğinde Matlab ve benzeri platformlarda kod yazılması işlem verimini artıracaktır. 


\section{KAYNAKLAR}

Al-Harthi, A.A., Al-Amri, R.M., Shehata, W.M. (1999). The porosity and engineering properties of vesicular basalt in Saudi Arabia. Engineering Geology 54: 313-320.

Al-Rousan T. M. (2004). Characterizatıon of aggregate shape properties usıng a computer automated system, Doctor of Philosophy, Texas A\&M University, Civil Engineering, 211, Texas.

Alshibli, K. A., Al-Hamdan, M. Z. (2001). Estimating volume change of triaxial soil specimens from planar images, Computer-Aided Civil and Infrastructure Engineering 16(6): 415-421.

Alshibli, K.A., Alsaleh, M.I. (2004). Characterizing surface roughness and shape of sands using digital microscopy, Journal of Computing in Civil Engineering 18 (1): 36-45.

Alshibli, K.A., Batiste, S.N., Sture, S. (2003). Strain localization in sand: plane strain versus triaxial compression, Journal of Geotechnical and Geoenvorimental Engineering, ASCE 129(6): 483-494.

Alshibli, K. A., Sture, S. (2000) Shear Band Formation in Plane Strain Experiments of Sand, ASCE, Journal of Geotechnical \& Geoenvironmental Engineering 126(6): 495503.

ASTM C97, Standard Test Methods for Absorption and Bulk Specific Gravity of Dimension Stone, ASTM Standards, ASTM International, Philadelphia, USA.

ASTM D 427-83, Standard test method for shrinkage factors of soil, ASTM Standards, ASTM International, Philadelphia, USA.

ASTM D 4943-02, Standard Test Method for Shrinkage Factors of Soils by the Wax Method, ASTM Standards, ASTM International, Philadelphia, USA.

Aydilek, A.H. (2006). A semi-analytical model for development of woven geotextile filter selection criteria. Geosynthetics Internationa, 13(2): 59-72.

Aydilek, A.H. Edil, T.B. (2004). Evaluation of Woven Geotextile Pore Structure Parameters Using Image Analysis, Geotechnical Testing Journal 27(1): 1-12.

Aydilek, A.H., Kutay, M.E., Sparacino, R., Dafla, H. (2007). Image Analysis for QC/QA of Geosynthetic Deformation during Wide Width Tensile Testing, Proceedings of Geosynthetics 2007, Washington, D.C.

Aydilek, A.H., Oguz, S.H., Edil, T.B. (2005). Constriction size of geotextile filters. Journal of Geotechnical and Geoenvironmental Engineering, ASCE 131(1): 28-38.

Baxes, G.A. (1994). Digital image processing, principles and applications. 452 s., John Wiley \& Sons, Inc., USA.

Beucher, S., Lantuejoul, C. (1979). Use of watersheds in contour detection. In the Proceedings of the international Workshop on Image Processing, Real-Time Edge and Motion Detection/Estimation, Rennes, France.

Bhatia, S., Soliman, A. (1990). Frequency distribution of void ratio of granular materials determined by an image analyzer, Soils and Foundations 30(1): 1-16.

Brzezicki, J., Kasperkiewicz, J. (1999). Automatic image analysis in evaluation of aggregate shape, Journal of Computing in Civil Engineering 13(2): 123-128.

Castelman, R. K. (1996). Digital image processing. Prentice hall, Englewood Cliffs, New Jersey, USA.

Cheng, Y.P., White, D.J., Bowman, E.T., Bolton, M.D., Soga, K. (2001). The observation of soil microstructure under load, 4th International Conference on Micromechanics of Granular Media-Powders \& Grains 2001, Kishino Y. (Ed): 69-72.

Crabtree, S.J., Ehrlich, Jr.R., Prince, C. (1984). Evaluation of strategies for segmentations of reservoir rocks, Computers Vision, Graphics and Image Processing 28(1): 1-18.

Dipova N. (2014). Digital Image Analysis Based Porosity Measurement On Macro-Porous Rocks, V. Global Stone Congress, Antalya, 22-25 Ekim 2014, pp.70-70

Dipova, N. (2017a). Determining the grain size distribution of granular soils using image analysis, Acta Geotechnica Slovenica 14: 28-37.

Dipova, N. (2017b). Görüntü analizi tekniklerinin serbest basınç dayanımı deneyinde kullanımı, 7. Geoteknik Sempozyumu 22-23-24 Kasım 2017, İstanbul.

Erhardt, A. (2000). Theory and Applications of Digital Image Processing, University of Applied Sciences, 54p.

Freilich, B., Zornberg, J.G. (2010). A Model for the Characterization of Scrap the Scrap Tire Bale Interface, Proceedings of the GeoFlorida 2010 Conference (GSP 199), Geo-Institute, ASCE, February 20-24, p. 2933-2942.

Frost, J.D., Jang, D.-J. (2000). Evolution of sand microstructure during shear. ASCE Jorurnal of Geotechnical and Geoenvironmental Engineering 126(2): 116-130.

Ghalib, A.M., Hryciw, R.D. (1999). Soil partical size distribution by mosaic imaging and watershed analysis, Journal of Computing in Civil Engineering13(2): 80-87.

Goodman, R. E., Ahlgren, C. S. (2000). Evaluating safety of concrete gravity dam on weak rock: Scott Dam, Journal of Geotechnical and Geoenvironmental Engineering 126(5): 429-442.

Gonzalez, R. F., Woods R. E. (2001). Digital Image Processing, Prentice Hall, USA.

Güler, M., Edil, T.B., Bosscher P.J. (1999). Measurement of particle movement in granular soils using image analysis, ASCE Journal of Computing in Civil Engineering 13 (2): 116-122.

Haneberg, W.C. (2004). Simulation of 3-D block populations to characterize outcrop sampling bias in block-in-matrix rocks (bimrocks), Felsbau-Rock and Soil Engineering 22: 19-26.

Hryciw R.D., Raschke S.A. (1996). Development of a computer vision technique for insitu soil chracterization, Transportation Research Record 1526: 86-97.

Hyoungkwan K., Haas, K.T., Rauch, A.F., Browne, C. (2003). 3D image segmentation of aggregates from laser profiling, Computer-Aided Civil and Infrastructure Engineering 18: 254-263.

Hu, R.L., Yue, Z.Q., Tham, L.G., Wang, L.C. (2005). Digital image analysis of dynamic compaction effects on clay fills, ASCE Journal of Geotechnical and GeoenvironmentalEngineering 131(11):1411-1422.

Kahraman, S., Alber, M., Fener, M., Gunaydin, O. (2010). The usability of Cerchar abrasivity index for the prediction of UCS and E of Misis Fault Breccia: Regression and artificial neural networks analysis, Expert Systems with Applications, 37: 8750-8756.

King, R.P. (1984). Measurement of particle size distribution by image analyser, Powder Technology 39(2): 279-289.

Kuo, C.Y., Frost, J.D. (1996). Uniformity evaluation of cohesionless specimens using digital image analysis. ASCE Journal of Geotechnical and Geoenvironmental Engineering 122(5), 390-396. 
Kwan, A.K.H., Mora, C.F. Chan, H.C. (1999). Particle shape analysis of coarseaggregate using digital image processing, Cement and Concrete Research 29(9): 1403-1410.

Macari, E. M., Parker, J. K., Costes, N. C. (1997). Measurement of volume changes in triaxial tests using digital imaging tecniques, Geotecnical Testing Journal 20(1): 103109.

Medley, E. W. (2002). Estimating block size distribution of melanges and similar block-in-matrix rocks (bimrocks). In R. Hammah, W. Bawden, J. Curran, \& M. Telesnicki (Eds.), Proceedings of the 5th North American rock mechanics symposium (pp. 509-516). Toronto, Canada: University of Toronto Press.

Mertens, G., Elsen, J. (2006). Use of computer assisted image analysis for the determination of the grain-size distribution of sands used in mortars, Cement and Concrete Research 36: 1453-1459.

Mora, C.F., Kwan, A.K.H., Chan, H.C. (1998). Particle size distribution analysis of coarse aggregate using digital image processing, Cement and Concrete Research 28(6), 921-932.

Mora, C.F., Kwan, A.K.H. (2000). Sphericity, Shape Factor, and Convexity Measurement of Coarse Aggregate for Concrete Using Digital Image Processing, Cement and Concrete Research 30(3): 351-358.

Muhunthan, B., Masad, E., Asaad, A. (2000). Measurement of uniformity and anisotropy in granular materials, Geotechncal Testing Journal 23(4), 423-431.
Nielsen, B.D. (2004). Non-Destructive soil testing using X-ray Computed Tomography, M.S. Thesis, Montana State University, Bozeman, Montana.

Ören, A. H., Önal, O., Özden, G., Kaya, A. (2006). Nondestructive evaluation of volumetric shrinkage of compacted mixtures using digital image analysis, Engineering Geology 85(3-4), 239-250.

Peng, X., Horn, R., Peth, S., Smucker, A. (2006). Quantification of soil shrinkage in 2D by digital image processing of soil surface, Soil and Tillage Research 91(1-2): 173-180.

Raschke, S. A., Hryciw R. D. (1997). Grain-size distribution of granular soils by computer vision, Geotechnical Testing Journal 20(4): 433-442.

Ruzyla, K. (1984). Characterization of pore space by quantitative image analysis, 59th annual technical conference and exhibition, Society of petroleum engineers of AIME, (SPE paper 13133), Houston-TX.

Tang, C., Shi, B., Liu, C., Zhao, L., Wang, B. (2208). Influencing factors of geometrical structure of surface shrinkage cracks in clayey soils, Engineering Geology 101(3-4): 204-217.

TS 699. Doğal yapı taşları - inceleme ve laboratuar deney yöntemleri, Türk Standardları Enstitüsü, Bakanlıklar, Ankara.

Vincent, L., Soille, P. (1991). Watersheds in digital spaces: an efficient algorithm based on immersion simulations. IEEE Trans Pattern Anal, 13: 583-9.

Young, I.T., Gerbrands, J.J., Viliet, L.J.V. (1998). Fundamentals of Image Processing, Delft University of Technology, ISBN 90-75691-01-7. 